\title{
Every Patient Tells a Story - Medical Mysteries and the Art of Diagnosis
}

\author{
Lisa Sanders \\ Barnes \& Noble (2009) \\ ISBN 978-07-679-2246-3
}

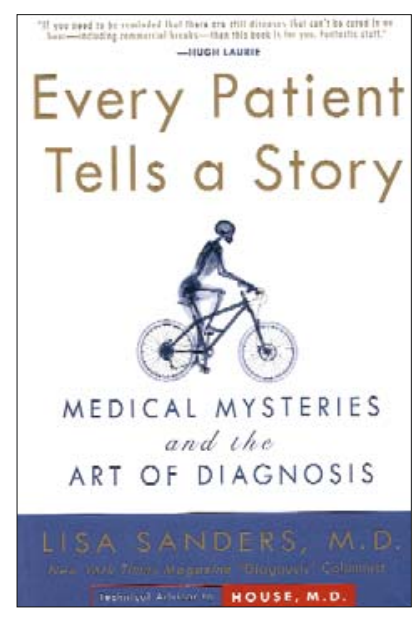
of Lyme disease, or the story about the first use of the stethoscope. Some of them are the stories of patients encountered during daily clinical practice, either by the author herself or some of her colleagues (she is from Yale University). You can feel through the pages the interest for investigation that has made the unconventional "Dr. House" so successful. If you are a clinician, you will find yourself trying to make the diagnosis before the author reveals it, and this "game" alone makes the book worthy of reading. An interesting note from the author: the equivocal and unfriendly personality of Dr. House is actually necessary to build up the stories, because a thorough and "sympathetic" doctor (one that considers a patient according to all his or her needs, so to speak) would reach the diagnosis much sooner. Moreover, there is another aspect which I find particularly interesting, and it has to do with the American system of medical education. In every case scenario mentioned, a major role is played by an intern or resident: it is not hard to see that most of the education process takes place during the 3 years of rResidency ("the time of your life where the only bed you can't learn from is yours"). In particular, the author seems interested in showing us how this has changed with changing medical practice: the increasing use of expensive diagnostic technologies, inevitably associated with the loss of the basic knowledge provided by the physical examination; the need to maximize time, which has obscured the centrality of the data-gathering process, with little interest for patient history and the physical examination; the fragmentation of healthcare; and much more. At this time when healthcare reform and increasing medical expenses are at the centre of public debate, I consider this book a good read for anyone like myself who thinks that a change in our system cannot be based on the indiscriminate cutting of expenses, but instead should rely on a new education which somehow has to look at the past and accept the innovation. The interest in teaching found in many of the people cited in the book gives hope to those who believe this process can really happen. 